\title{
A shed form of LDL receptor-related protein-1 regulates peripheral nerve injury and neuropathic pain in rodents
}

\author{
Alban Gaultier, ${ }^{1}$ Sanja Arandjelovic, ${ }^{1}$ Xiaoqing Li, ${ }^{2}$ Julie Janes, ${ }^{2}$ Nikola Dragojlovic, ${ }^{1}$ \\ George P. Zhou, ${ }^{2}$ Jenny Dolkas, ${ }^{2}$ Robert R. Myers, ${ }^{1,2}$ Steven L. Gonias, ${ }^{1}$ and W. Marie Campana ${ }^{2}$
}

${ }^{1}$ Department of Pathology and 2Department of Anesthesiology, UCSD School of Medicine, La Jolla, California, USA.

\begin{abstract}
Injury to the peripheral nervous system (PNS) initiates a response controlled by multiple extracellular mediators, many of which contribute to the development of neuropathic pain. Schwann cells in an injured nerve demonstrate increased expression of LDL receptor-related protein-1 (LRP1), an endocytic receptor for diverse ligands and a cell survival factor. Here we report that a fragment of LRP1, in which a soluble or shed form of LRP1 with an intact $\alpha$-chain (sLRP- $\alpha$ ), was shed by Schwann cells in vitro and in the PNS after injury. Injection of purified sLRP- $\alpha$ into mouse sciatic nerves prior to chronic constriction injury (CCI) inhibited p38 MAPK activation (P-p38) and decreased expression of TNF- $\alpha$ and IL-1 $\beta$ locally. sLRP- $\alpha$ also inhibited CCI-induced spontaneous neuropathic pain and decreased inflammatory cytokine expression in the spinal dorsal horn, where neuropathic pain processing occurs. In cultures of Schwann cells, astrocytes, and microglia, sLRP- $\alpha$ inhibited TNF- $\alpha$-induced activation of p38 MAPK and ERK/MAPK. The activity of sLRP- $\alpha$ did not involve TNF- $\alpha$ binding, but rather glial cell preconditioning, so that the subsequent response to TNF- $\alpha$ was inhibited. Our results show that sLRP- $\alpha$ is biologically active and may attenuate neuropathic pain. In the PNS, the function of LRP1 may reflect the integrated activities of the membrane-anchored and shed forms of LRP1.
\end{abstract}

\section{Introduction}

The LDL receptor-related protein-1 (LRP1) is a member of a gene family found in diverse species, including mammals, C. elegans, Drosophila, and Xenopus (1-4). Receptors in this family regulate development (4-6) and the progression of various diseases, including atherosclerosis, Alzheimer disease, and cancer (7-9). LRP1 is synthesized as a single-chain $600-\mathrm{kDa}$ type I transmembrane receptor and processed by a furin-like protease into the mature 2-chain form. The $515-\mathrm{kDa} \alpha$-chain is entirely extracellular but coupled by strong noncovalent interactions to the $85-\mathrm{kDa}$ transmembrane $\beta$-chain (10). The structure of the $\alpha$-chain includes binding sites for over 40 ligands, including proteases, protease inhibitors, lipoprotein particles, growth factors, and extracellular matrix proteins $(1,11)$. The $\beta$-chain includes intracellular binding sites for signaling adaptor proteins such as Shc, c-Jun aminoterminal kinaseinteracting protein (JIP), and disabled-1 (12-14).

The function of LRP1 as an endocytic receptor for diverse extracellular mediators represents one mechanism by which LRP1 may regulate the cellular microenvironment in injury and inflammation. LRP1 also may regulate the response to injury by facilitating endocytosis of other transmembrane receptors involved in cell signaling (15). Finally, LRP1 directly regulates cell signaling and gene transcription by its capacity to bind signaling adaptor proteins (1, 16). In the CNS, LRP1 regulates the permeability of the blood-brain barrier $(17,18)$ and clears $\beta$-amyloid peptide from the neuropil $(19)$.

Nonstandard abbreviations used: CCI, chronic constriction injury; CM, conditioned medium; GFAP, glial fibrillary acidic protein; GST, glutathione-s-transferase; LRP1, LDL receptor-related protein-1; PNS, peripheral nervous system; P-p38, p38 MAPK activation; RAP, receptor-associated protein; SBTI, biotin-labeled soybean trypsin inhibitor; sLRP- $\alpha$, a soluble or shed form of LRP1 with an intact $\alpha$-chain. Conflict of interest: The authors have declared that no conflict of interest exists. Citation for this article: J. Clin. Invest. 118:161-172 (2008). doi:10.1172/JCI32371.
In the peripheral nervous system (PNS), LRP1 promotes Schwann cell survival by regulating the activity of PI3K (20).

LRP1 may be released from the cell surface by transmembrane metalloproteinases such as MT1-MMP (21). This reaction occurs near the center of the LRP1 $\alpha$-chain, inactivating the ligand-binding function of the receptor. The LRP1 $\beta$-chain is a target for BACE-like proteases $(22,23)$, which are known to be present in the PNS (24). Cleavage of the $\beta$-chain releases a shed form of the receptor with an apparently intact $\alpha$-chain. A soluble or shed form of LRP1 with an intact $\alpha$-chain (sLRP- $\alpha$ ) is present in human plasma (25) and has been identified at the blood-brain barrier in ischemia (17). Given the diverse activities of membrane-anchored LRP1, it is reasonable to hypothesize that LRP1 shedding alters cell physiology by loss of function. The possibility that sLRP- $\alpha$ expresses novel biological activities is less clear.

PNS injury generates a microenvironment rich in extracellular mediators, including proteases and cytokines $(26,27)$. The proper balance of factors is essential to ensure the unique capacity of the PNS for regeneration (28). Imbalances may have severe consequences, including the development of chronic neuropathic pain states, associated with conditions such as sciatica $(29,30)$. Neuropathic pain is refractory to analgesic therapy. Thus understanding the molecular foundation for neuropathic pain is essential to facilitate the development of novel therapeutics. In PNS injury, TNF- $\alpha$ plays a central role, orchestrating many of the events involved in Wallerian degeneration and sensitizing nociceptors (31-33). In fact, neuropathic pain states have been modeled by direct administration of TNF- $\alpha$ into uninjured sciatic nerves $(34,35)$.

Here we demonstrate that SLRP- $\alpha$ is generated by primary Schwann cells in culture and in the PNS after nerve injury. Furthermore, we provide evidence for what we believe to be the first time that sLRP- $\alpha$ is biologically active in the PNS. Direct injection 
A

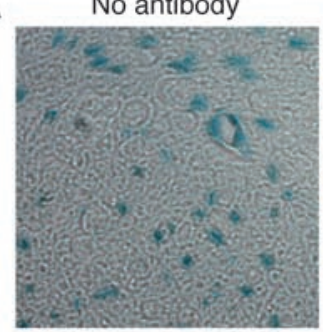

Day 3

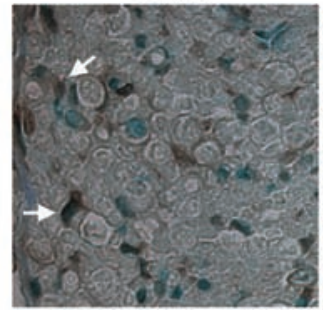

B

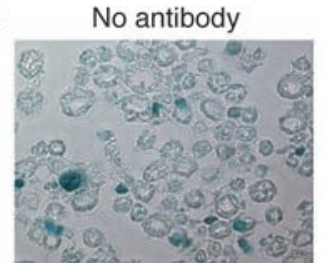

Day 3

C

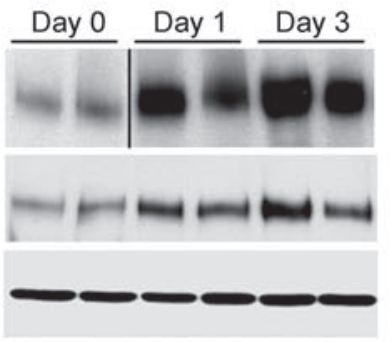

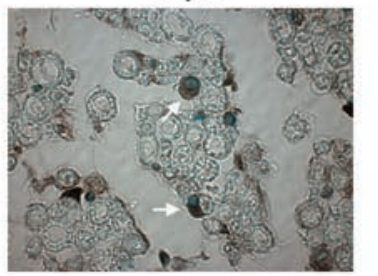

Day 0

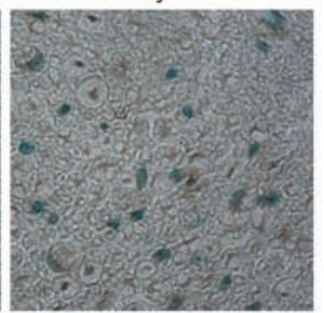

Day 5

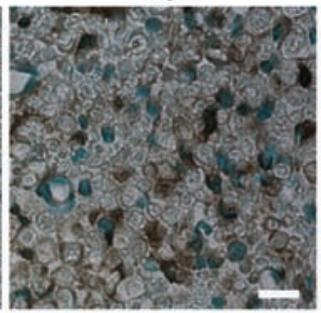

Day 0

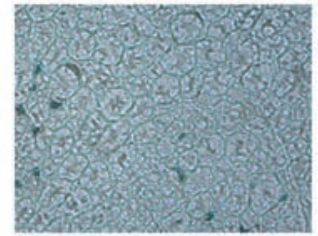

RAP

ligand blot

LRP-1

$\alpha$-chain

$\beta$-actin

\section{Figure 1}

Immunohistochemical analysis of LRP1 $\alpha$-chain in adult mouse and rat sciatic nerve. (A) LRP1 $\alpha$-chain in mouse sciatic nerve after $\mathrm{CCI}$. Photomicrographs were prepared at $\times 400$ magnification and are representative of $n=4 /$ group. Scale bar: $45 \mu \mathrm{m}$. The white arrows demarcate Schwann cells that are increasingly immunopositive for LRP1 $\alpha$-chain after injury. (B) Immunohistochemical analysis of LRP1 $\alpha$-chain in rat sciatic nerve after crush injury. Photomicrographs were prepared at $\times 400$ magnification and are representative of $n=4 /$ group. Sections are of nerve immediately distal to the injury site. The white arrows demarcate Schwann cell cytoplasm that is increasingly immunopositive for LRP1 after injury. (C) Protein extracts from uninjured and crush-injured rat sciatic nerves were examined by RAP ligand blotting and immunoblot analysis for LRP1 $\alpha$-chain. The same extracts were probed for $\beta$-actin as a loading control. Two representative samples from different animals at each day are shown ( $n=6-9 /$ group). of sLRP- $\alpha$ into sciatic nerves prior to chronic constriction injury (CCI) inhibits p38 MAPK activation (P-p38) locally, decreases expression of inflammatory cytokines at the injury site, and inhibits spontaneous pain-related behaviors after nerve injury. Inflammatory cytokine expression also is decreased in the spinal dorsal horn, a major site of processing. sLRP- $\alpha$ was active in cell culture, inhibiting TNF- $\alpha$ expression by Schwann cells in response to endotoxin and cell signaling in Schwann cells, astrocytes, and microglia in response to TNF- $\alpha$. These results demonstrate for what we believe to be the first time that the integrated function of LRP1 in the PNS may reflect activities of both the membraneanchored and shed forms of the receptor.

\section{Results}

$L R P 1 \alpha$-chain levels increase in injured rat sciatic nerve. In uninjured rat sciatic nerve, LRP1 $\beta$-chain immunoreactivity localizes mainly to axoplasm (20). After nerve crush injury, which causes fulminant axonal degeneration, LRP1 $\beta$-chain immunoreactivity is substantially increased in Schwann cells, accompanied by an increase in LRP1 mRNA; however, the total level of LRP1 $\beta$-chain in the nerve, as determined by immunoblot analysis, is decreased by about $50 \%$, probably reflecting loss of LRP1 protein from axons.

In this study we examined mouse sciatic nerve before and after CCI, which is a model of partial axonal degeneration accompanied by extensive inflammation (36). We used polyclonal antibody 2629 , which recognizes the $515-\mathrm{kDa}$ LRP1 $\alpha$-chain, as opposed to the $\beta$-chain $(20,37)$. In the uninjured mouse nerve, LRP1 $\alpha$-chain immunoreactivity was localized primarily to axoplasm and, to a lesser extent, to other resident endoneural cells including Schwann cells (Figure 1A). Following CCI, LRP1 $\alpha$-chain immunoreactivity was greatly increased in Schwann cells (Figure 1A). By day 5, the broad level of LRP $\alpha$-chain immunopositivity probably reflected nucleated cells in addition to Schwann cells, including macrophages and other inflammatory cells that are abundant on day 5 at the CCI site (27) (Figure 1A).

The increase in Schwann cell LRP1 $\alpha$-chain observed after CCI in the mouse was consistent with our earlier finding that Schwann cell LRP1 $\beta$-chain is increased following crush injury in rats (20). To confirm this correlation, we reexamined naive and crushed rat nerve by immunohistochemistry, using $\alpha$-chain-specific antibody. In uninjured rat nerve, axons and other resident endoneural cells were immunopositive for LRP1 $\alpha$-chain (Figure 1B). Three days after crush injury, LRP1 $\alpha$-chain immunoreactivity was substantially increased primarily in association with Schwann cells (Figure 1B).

To estimate the total level of LRP1 $\alpha$-chain in sciatic nerve before and after crush injury whole nerve extracts were subjected to ligand blotting with glutathione-s-transferase receptor-associated protein (GST-RAP). RAP is an intracellular chaperone that binds tightly to the LRP1 $\alpha$-chain, with the pitfall that other members of the LDL receptor family are also detected $(38,39)$. In uninjured rat sciatic nerve, a single band with an apparent mass equivalent to that of the LRP1 $\alpha$-chain was observed (Figure 1C). The level of this RAPbinding species increased after nerve injury. Immunoblot analysis using LRP1 $\alpha$-chain-specific antibody confirmed that the $\alpha$-chain is increased in crushed nerve. Because the LRP1 $\alpha$-chain is increased in crushed nerve (Figure 1) and the $\beta$-chain is decreased (20), we hypothesized that the $\alpha$-chain may be shed and remain stable in the extracellular microenvironment of the injured peripheral nerve.

LRP $1 \alpha$-chain is shed from Schwann cells. Primary cultures of rat Schwann cells were transferred to serum-free medium for 6 hours. 
A

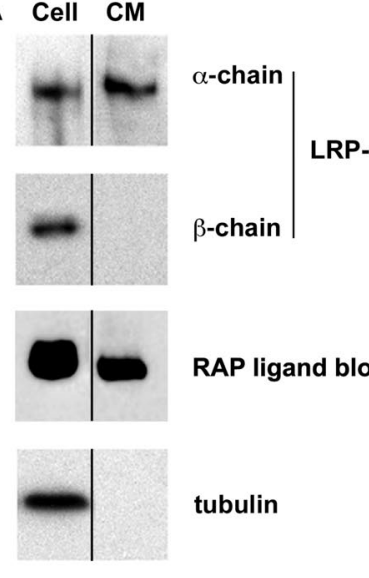

B

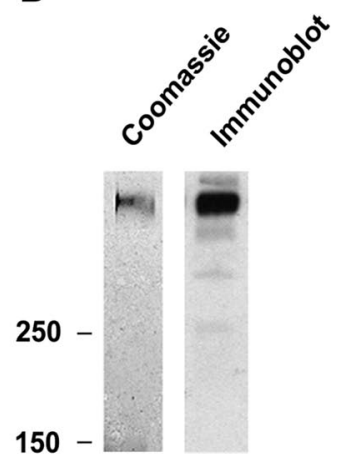

\section{Figure 2}

LRP1 $\alpha$-chain is shed into Schwann cell CM. (A) Immunoblot analysis of cell extracts (cell) and CM after $6 \mathrm{~h}$ of incubation in serum-free medium. LRP1 $\alpha$-chain $(515 \mathrm{kDa})$ was detected using antibody 2629. LRP1 $\beta$-chain $(85 \mathrm{kDa}$ ) was detected using antibody $11 \mathrm{H} 4$. The LRP1 $\alpha$-chain also was detected by RAP ligand blotting. The mass of the band detected by RAP ligand blotting of cell extracts and CM was equivalent to that detected with antibody 2629. The same blots were probed for tubulin. These blots are representative of 3-5 independent studies. (B) SDS-PAGE and Coomassie staining of protein (sLRP- $\alpha$ ) purified from human plasma by RAP-affinity chromatography. The same preparation was subjected to immunoblot analysis with antibody 2629.
The conditioned medium (CM) was concentrated and subjected to RAP ligand blotting and immunoblot analysis with antibody 2629. As shown in Figure 2A, a band with an apparent mass equivalent to that of cell-associated LRP1 $\alpha$-chain was detected in the CM. To ensure that the detected band represented SLRP- $\alpha$ and not intact LRP1 associated with cell membrane fragments, immunoblot analysis was performed with antibody $11 \mathrm{H} 4$, which detects the intracytoplasmic domain of LRP1 $\beta$-chain. These immunoblots were negative. Tubulin also was not detected in the CM, again excluding detached cells or cell fragments as the source of the LRP1 $\alpha$-chain. We concluded that a shed form of LRP1 with an intact $\alpha$-chain but lacking at least part of the $\beta$-chain was released from Schwann cells in vitro.

sLRP- $\alpha$ is biologically active in vivo and in vitro. sLRP- $\alpha$ was purified from human plasma by affinity chromatography, using GST-RAP coupled to Sepharose $(25,40)$. The final preparation was subjected to SDS-PAGE/Coomassie staining and immunoblot analysis with antibody 2629, confirming its purity (Figure 2B). The mobility of the $\alpha$-chain in purified sLRP- $\alpha$ was equivalent to that of LRP1 $\alpha$-chain in Schwann cell CM (data not shown). The sequence homology of rat and human LRP1 is greater than $90 \%$.

To determine the function of SLRP- $\alpha$ in nerve injury in vivo, we injected purified sLRP- $\alpha$ (5 $\mu \mathrm{g}$ in $2 \mu \mathrm{l}$ ) or vehicle directly into mouse nerves prior to CCI. Whole nerve extracts were prepared 24 hours later and subjected to immunoblot analysis to detect P-p38, a marker of activated Schwann cells at the injury site (41). P-p38 is required for Schwann cell expression of TNF- $\alpha$ $(41,42)$. Figure 3 A shows that P-p38 was substantially increased following CCI in vehicle-treated mice. When nerves were treated with sLRP- $\alpha$, the increase in P-p38 was inhibited. Densitometric analysis of P-p38 standardized against the axonal marker PGP9.5 is shown in Figure 3B. P-p38 was decreased by approximately $60 \%$ when the nerves were pretreated with sLRP- $\alpha(P<0.01)$.

Figure 3
A

Most LRP1 ligands bind to clusters of complement-like repeats in the $\alpha$-chain, which may be fully blocked by GST-RAP $(1,11,38$, 39). Two protocols were executed to test whether GST-RAP inhibits the activity of sLRP- $\alpha$ in vivo in the injured nerve. First, we incubated sLRP- $\alpha$ with an 8 -fold molar excess of GST-RAP for 30 min-
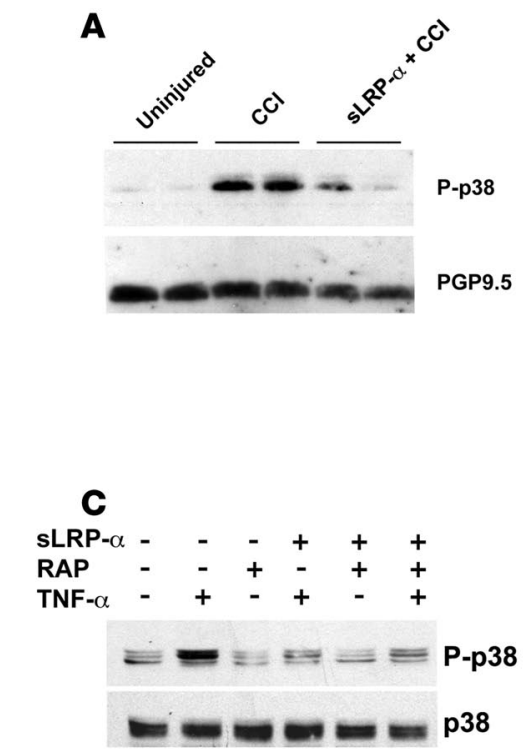

D
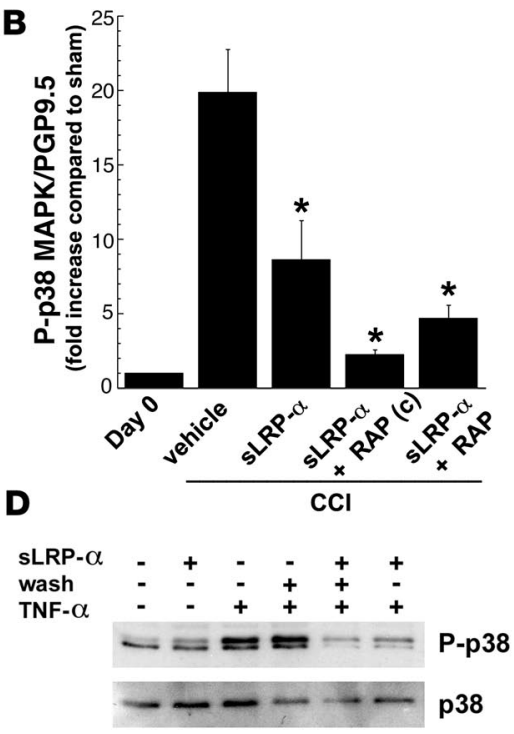

sLRP- $\alpha$ regulates cell signaling in vivo and in vitro. (A) Sciatic nerve was recovered from mice that were uninjured (sham) and from mice that were subjected to $\mathrm{CCl}$ for $24 \mathrm{~h}$. The mice that received $\mathrm{CCl}$ were treated with SLRP- $\alpha(\mathrm{CCl}+\mathrm{SLRP}-\alpha)$ or vehicle $(\mathrm{CCl})$ immediately prior to tightening the sutures. Immunoblot analysis shows P-p38 and PGP9.5, an axonal marker and loading control. (B) Densitometric analysis of the ratio of P-p38 to PGP9.5 in uninjured (day 0) vehicle-treated nerve that was subjected to $\mathrm{CCI}$, SLRP- $\alpha-$ treated nerve subjected to $\mathrm{CCl}, \mathrm{CCl}$ nerve treated with purified SLRP- $\alpha-R A P$ complex, and $\mathrm{CCI}$ nerve that was treated with preincubated but not purified SLRP- $\alpha-\operatorname{RAP}$ complex $(n=4 /$ group; ${ }^{*} P<0.01$ compared with vehicle-treated $\mathrm{CCl}$ animals). (C) Extracts from primary Schwann cells were subjected to SDS-PAGE and immunoblot analysis to detect P-p38 and total p38. The cells were treated with SLRP- $\alpha(50 \mathrm{nM})$ or vehicle for $10 \mathrm{~min}$ prior to adding TNF- $\alpha(1.0 \mathrm{nM})$ for $10 \mathrm{~min}$. In some cases, the sLRP- $\alpha$ was preincubated with RAP (200 $\mathrm{nM}$ ) at $37^{\circ} \mathrm{C}$ prior to treating Schwann cells. (D) Extracts from Schwann cells in culture were subjected to SDS-PAGE and immunoblot analysis to detect P-p38 and total p38. The cells were first treated with SLRP- $\alpha(50 \mathrm{nM})$ or vehicle for $10 \mathrm{~min}$ and then with TNF- $\alpha$ for $10 \mathrm{~min}$. In some cases, cells were washed after treatment with SLRP- $\alpha$ and prior to treatment with TNF- $\alpha$. The blots shown are representative of 3 independent studies. 


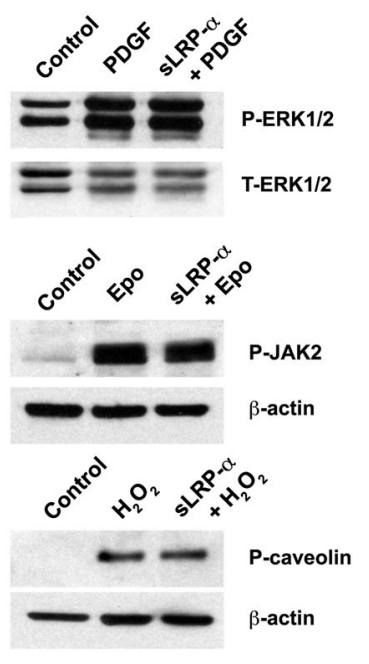

utes at $37^{\circ} \mathrm{C}$. The complex was purified by molecular exclusion chromatography for intraneural injection. In the second protocol, sLRP- $\alpha$ was pretreated with a 2 -fold molar excess of GST-RAP and injected without purification. In both cases, the ability of sLRP- $\alpha$ to antagonize P-p38 was not inhibited by GST-RAP $(P<0.001)$.

Our in vivo experiments suggested that sLRP- $\alpha$ may counteract Schwann cell activation in response to injury. To test this hypothesis, we studied primary Schwann cell cultures (43), which are known to model Schwann cells in the injured peripheral nerve (44). Figure 3C shows that TNF- $\alpha(1 \mathrm{nM})$ induced P-p38 in Schwann cells as anticipated. sLRP- $\alpha$ did not independently regulate P-p38; however, pretreatment of Schwann cells with sLRP- $\alpha$ for $10 \mathrm{~min}-$ utes prior to adding TNF- $\alpha$ blocked P-p38 in response to TNF- $\alpha$. The activity of sLRP- $\alpha$, as an antagonist of TNF- $\alpha$-induced P-p38, was not inhibited by GST-RAP, arguing against a mechanism in which sLRP- $\alpha$ binds ligands in the Schwann cell medium.

Because GST-RAP did not block the activity of sLRP- $\alpha$, we hypothesized that SLRP- $\alpha$ may inhibit the Schwann cell response to TNF- $\alpha$ by a mechanism that requires binding to the Schwann cell surface. To test this hypothesis, cells were treated with sLRP- $\alpha$ for 10 minutes, washed, and then treated with TNF- $\alpha$. Because of the washing step, sLRP- $\alpha$ was not available to bind TNF- $\alpha$ in solution; however, the sLRP- $\alpha$ still substantially inhibited P-p38 in response to TNF- $\alpha$ (Figure 3D). These results support a model in which the effects of SLRP- $\alpha$ on TNF- $\alpha$ activity are not due to sequestration of exogenously added TNF- $\alpha$, but rather a direct interaction with the Schwann cells. In support of this model, we radioiodinated TNF- $\alpha$ and applied a number of techniques to identify an interaction with SLRP- $\alpha$ (coimmunoprecipitation, ligand blotting, and immobilization). Binding was not observed (data not shown).

To determine whether the effects of SLRP- $\alpha$ on the response to TNF- $\alpha$ were specific, we tested the ability of sLRP- $\alpha$ to antagonize other cell-signaling responses in Schwann cells. Pretreatment of the Schwann cells with sLRP- $\alpha$ for 10 minutes did not inhibit activation of ERK/MAPK in response to platelet-derived growth factor, phosphorylation of the nonreceptor tyrosine kinase JAK2 by erythropoietin, or phosphorylation of caveolin in response to $\mathrm{H}_{2} \mathrm{O}_{2}$ (Figure 4).

sLRP- $\alpha$ binds to Schwann cells. To demonstrate that sLRP- $\alpha$ binds directly to cultured Schwann cells, FITC-labeled sLRP- $\alpha(50 \mathrm{nM})$ was incubated with cells for 10 minutes at $37^{\circ} \mathrm{C}$. FITC-labeling

\section{Figure 4}

sLRP- $\alpha$ selectively regulates TNF- $\alpha-$ initiated cell signaling. Top: Protein extracts from Schwann cells in culture were subjected to SDSPAGE and immunoblot analysis to detect phosphorylated ERK1/2 (P-ERK1/2) and total ERK1/2 (T-ERK1/2). The cells were first treated with sLRP- $\alpha(50 \mathrm{nM})$ or vehicle for 10 min prior to adding PDGF-BB $(1.0 \mathrm{nM})$ for $10 \mathrm{~min}$. Control cells were not treated with PDGF. Middle: Schwann cells were pretreated with SLRP- $\alpha(50 \mathrm{nM})$ or vehicle for 10 $\mathrm{min}$ and then with $1.0 \mathrm{nM}$ erythropoietin (Epo) for $10 \mathrm{~min}$. Immunoblot analysis was performed to detect P-JAK2 and $\beta$-actin. Bottom: Immunoblot analysis was performed to detect $\mathrm{P}$-caveolin and $\beta$-actin. The cells were first treated with SLRP- $\alpha(50 \mathrm{nM})$ or vehicle for $10 \mathrm{~min}$ prior to adding $0.15 \mathrm{mM} \mathrm{H}_{2} \mathrm{O}_{2}$ for $10 \mathrm{~min}$. The blots shown are representative of 2 independent studies.

avoided the use of antibodies, which may bind nonspecifically to the cells. Fluorescence microscopy showed that even with a limited incubation time, sLRP- $\alpha$ became cell associated (Figure 5A). To better quantitate this interaction, FITC-labeled sLRP- $\alpha$ binding to Schwann cells was determined by FACS analysis. These studies were conducted at $4^{\circ} \mathrm{C}$ to assure that cell surface binding of sLRP- $\alpha$ was not followed by internalization. Figure $5 \mathrm{~B}$ shows that FITC-labeled sLRP- $\alpha$ bound to all of the Schwann cells and not just a subpopulation (results were representative of 5 independent experiments). As a negative control, we also studied a FITC-labeled IgG specific for GFP. Little or no binding was detected by FACS. Preincubation of GST-RAP with the FITC-labeled sLRP- $\alpha$ failed to inhibit binding to the Schwann cells and in some experiments increased binding. Purified GST had no effect.

Next we tested whether SLRP- $\alpha$ inhibits the interaction of TNF- $\alpha$ with Schwann cells. Cell surface binding of TNF- $\alpha$ is mediated by 2 major receptors (45) that are located in Schwann cells (28). Biotin-labeled TNF- $\alpha$ was incubated with Schwann cells for 1 hour at $4^{\circ} \mathrm{C}$. The cells were then treated with FITC-labeled streptavidin at $4^{\circ} \mathrm{C}$ for 30 minutes. Figure $5 \mathrm{C}$ shows that TNF- $\alpha$ binding was detected by FACS. As a negative control, no binding was observed with biotin-labeled soybean trypsin inhibitor (SBTI). sLRP- $\alpha$ partially inhibited the binding of TNF- $\alpha$ to the Schwann cells, and this activity was not inhibited by preincubation with GST-RAP. The results of the 6 independent experiments with sLRP- $\alpha$ and biotin-labeled TNF- $\alpha$ are summarized in Figure 5D. Binding was inhibited by $39 \% \pm 7 \%(P<0.05)$.

Regulation of cytokine expression in vitro and in vivo. Following nerve injury Schwann cells express inflammatory cytokines, partially under the control of P-p38 $(46,47)$. To test whether sLRP- $\alpha$ inhibits cytokine expression in the injured nerve, $5 \mu \mathrm{g}$ of sLRP- $\alpha$ or vehicle were injected directly into the nerve immediately prior to CCI. Tissue samples from the CCI site and within $2 \mathrm{~mm}$ downstream of the injury site were recovered 1, 3, and 5 days later for RNA harvesting. Because axons have limited amounts of mRNA and Schwann cells comprise $90 \%$ of the nucleated cells in the peripheral nerve (48), mRNA harvested from uninjured nerves and from CCI nerves within 24 hours of injury reflects mainly Schwann cell expression. At later time points, inflammatory cells enter the nerve.

As shown in Figure 6, in sciatic nerves that were subjected to CCI and injected with vehicle, the mRNAs for TNF- $\alpha$ and IL- $1 \beta$ were 
A
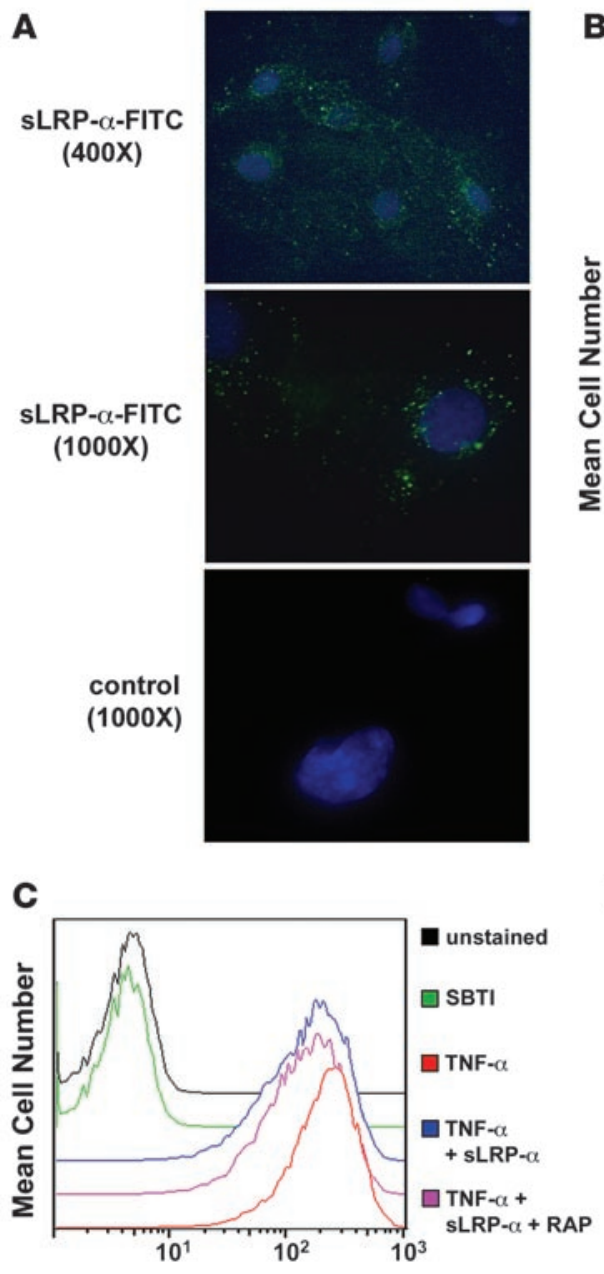

Fluorescence Intensity
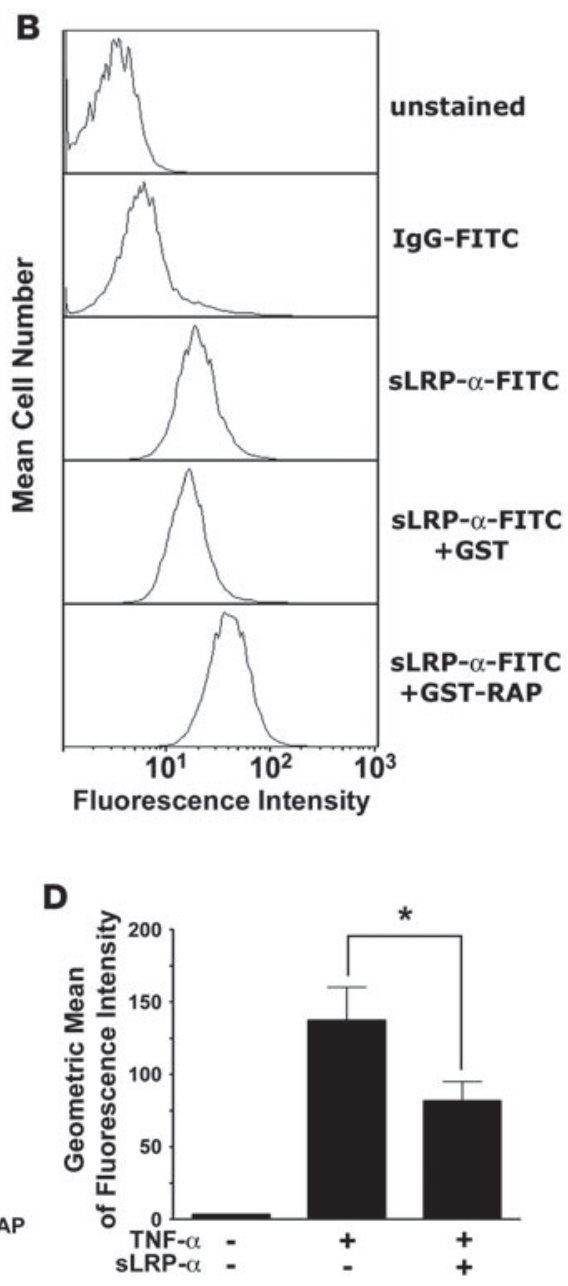

\section{Figure 5}

sLRP- $\alpha$ binds to Schwann cells in vitro and partially inhibits TNF- $\alpha$ binding. (A) Schwann cells were treated with FITC-labeled SLRP- $\alpha$ (green) or vehicle for $10 \mathrm{~min}$ at $37^{\circ} \mathrm{C}$. The cells were washed, fixed, and visualized by fluorescence microscopy. Cell nuclei were stained by DAPI (blue). (B) Schwann cells were treated with 50 nM FITC-labeled SLRP- $\alpha$ (sLRP- $\alpha-$ FITC), $50 \mathrm{nM}$ FITC-labeled IgG (IgG-FITC), or vehicle (unstained) for $1 \mathrm{~h}$ at $4^{\circ} \mathrm{C}$. In some cases FITClabeled SLRP- $\alpha$ was preincubated with $100 \mathrm{nM}$ GST (sLRP- $\alpha-F I T C+$ GST) or 100 nM GSTRAP (sLRP- $\alpha-F I T C+G S T-R A P)$ for $15 \mathrm{~min}$ at $22^{\circ} \mathrm{C}$ prior to incubation with cells. The cells were then washed and subjected to FACS. (C) Schwann cells were incubated with $50 \mathrm{nM}$ sLRP- $\alpha$ for $15 \mathrm{~min}$ at $22^{\circ} \mathrm{C}$. In some cases, SLRP- $\alpha$ was preincubated with $100 \mathrm{nM}$ GSTRAP (sLRP- $\alpha+$ RAP) for 30 min at $37^{\circ} \mathrm{C}$ prior to incubation with the cells. Biotin-labeled TNF- $\alpha$ or vehicle (unstained) was then incubated with the cells for $1 \mathrm{~h}$ at $4^{\circ} \mathrm{C}$. SBTI was incubated with separate cells as a negative control. FITC-labeled streptavidin was added for 30 $\min$ at $4^{\circ} \mathrm{C}$. The cells were then washed and subjected to FACS. (D) Schwann cells were incubated with SLRP- $\alpha(+)$ or vehicle (-) for 15 $\min$ at $22^{\circ} \mathrm{C}$. Biotin-labeled recombinant human TNF- $\alpha$ was added to some cells for $1 \mathrm{~h}$ at $4^{\circ} \mathrm{C}$, followed by FITC-labeled streptavidin. Cells were washed and subjected to FACS. Data was analyzed using the FlowJo software, and the geometric mean of FITC fluorescence intensity is plotted. ${ }^{*} P<0.05$ for reduction in TNF- $\alpha$ binding to Schwann cells compared with vehicle treatment (5-6 independent experiments). significantly elevated at 24 hours $(P<0.01)$ compared with control nerves that were not subjected to CCI. At days 3 and 5, a gradual reduction in the level of mRNA for both cytokines was observed, as has been previously described (49). In mice that were treated with sLRP- $\alpha$, the mRNA levels for TNF- $\alpha$ and IL-1 $\beta$ still were increased at 24 hours; however, the magnitude of the increase was significantly less than that observed in vehicle-treated animals $(P<0.05)$. The activity of sLRP- $\alpha$ was no longer apparent 3 and 5 days after injury. This may reflect the half-life of sLRP- $\alpha$ in the nerve and the fact that the animals were treated only once prior to CCI.

In cell culture, Schwann cells express high levels of TNF- $\alpha$ when challenged with lipopolysaccharide (LPS/endotoxin) (50). To test whether SLRP- $\alpha$ inhibits TNF- $\alpha$ expression in vitro, we treated primary cultures of Schwann cells with LPS, sLRP- $\alpha$, or a combination of LPS and SLRP- $\alpha$ for 4 hours. LPS induced a substantial increase in TNF- $\alpha$ mRNA expression (Figure 6C) as anticipated $(50,51)$. sLRP- $\alpha$ alone did not regulate TNF- $\alpha$ expression; however, sLRP- $\alpha$ significantly inhibited the increase in TNF- $\alpha$ mRNA expression associated with LPS treatment. Although a variety of lipid A-binding proteins and peptides have been described, including LDL (52), we hypothesized that SLRP- $\alpha$ desensitized the cell in its ability to respond to LPS. To test this hypothesis, we conducted a washout experiment similar to that performed in analyzing P-p38. When Schwann cells were pretreated with sLRP- $\alpha$, washed, and then treated with LPS, TNF- $\alpha$ mRNA expression was significantly decreased compared with that observed in cells that were not treated with SLRP- $\alpha$. Preincubation of sLRP- $\alpha$ with GST-RAP did not block the bioactivity of sLRP- $\alpha$ in the in vitro LPS challenge model.

$s L R P-\alpha$ regulates spontaneous neuropathic pain. TNF- $\alpha$ plays a significant role in the development of neuropathic pain states $(35,53$, $54)$. Because sLRP- $\alpha$ regulated $\mathrm{p} 38$ MAPK activation and cytokine expression in vivo, we conducted experiments to determine whether sLRP- $\alpha$ regulates pain following CCI. Spontaneous pain-related behavior was measured for 2 weeks following surgery. Spontaneous pain was scored based on observation of animal behavior. Figure 7A shows typical spontaneous pain-related behavior in a cohort of C57BL/6J mice subjected to CCI without any form of therapy. Pain scores were maximal 2 days following surgery and reduced gradually over the next 13 days.

Next we injected purified sLRP- $\alpha$ ( 1 or $5 \mu \mathrm{g}$ in $2 \mu \mathrm{l}$ ) or vehicle directly into the sciatic nerves of acclimated mice prior to CCI. Spontaneous pain-related behavior was monitored for 4 days (Figure 7B). sLRP- $\alpha$ at both doses consistently decreased the pain score at all 4 time points; the decreases at days 3 and $4(\sim 50 \%)$ were statistically significant $(P<0.05)$. A lower sLRP- $\alpha$ dose $(0.2$ $\mu \mathrm{g})$ was not effective at reducing spontaneous pain scores (data not shown). In these experiments, mice demonstrating detectable 
A

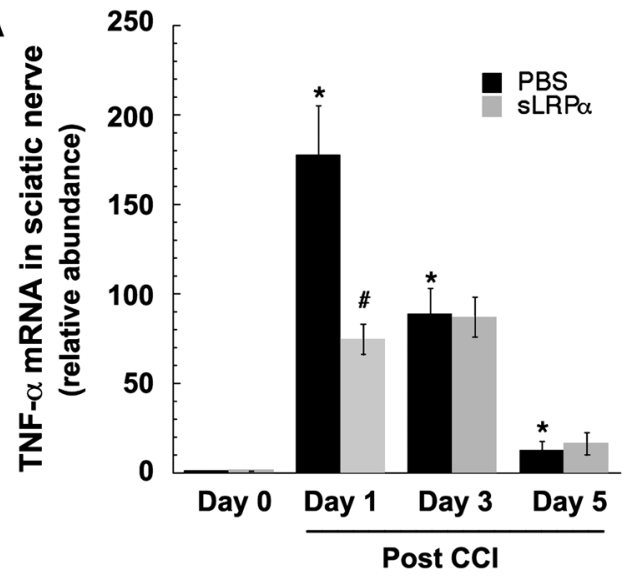

B

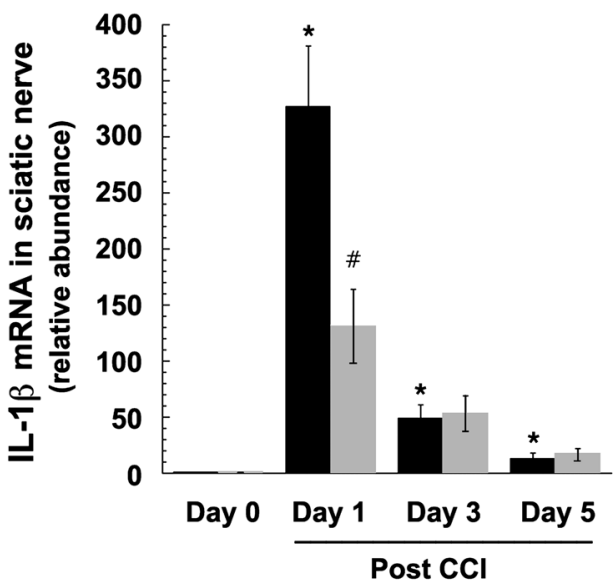

C

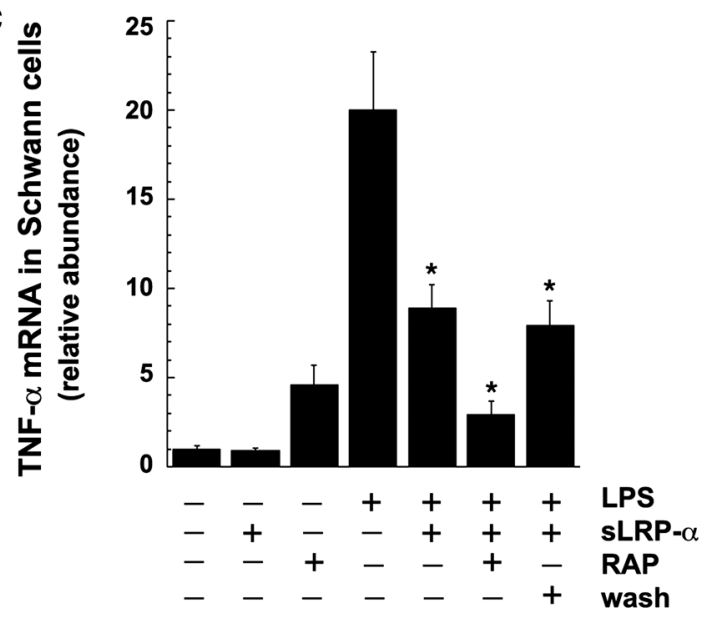

motor abnormalities were excluded to minimize the impact of this factor on our spontaneous pain scores.

Peripheral nerve injury and neuropathic pain are associated with changes in proinflammatory cytokine expression in the superficial dorsal horn of the spinal cord (55). In our next series of studies, mice were subjected to CCI immediately following injection of sLRP- $\alpha$ or vehicle into the nerve fascicle. The superficial dorsal horn was recovered and RNA was isolated 1 or 5 days following surgery. Figure 7C shows that in vehicle-treated animals, TNF- $\alpha$ mRNA was significantly increased (1.5- to 1.8 -fold). A 1.5 -fold increase in IL-1 $\beta$ mRNA was observed at day 1. A single injection

\section{Figure 6}

sLRP- $\alpha$ antagonizes proinflammatory cytokine expression at the injury site in $\mathrm{CCl}$ and in Schwann cells treated with LPS in culture. TNF- $\alpha$ mRNA levels (A) and IL-1 $\beta$ mRNA levels (B) were determined in untreated nerve (day 0 ) and following $\mathrm{CCl}$. Mice were injected with vehicle or SLRP- $\alpha(5 \mu \mathrm{g})$ directly into the nerve prior to $\mathrm{CCl}$. ${ }^{*} P<0.05$, vehicle-treated animals at the indicated day versus uninjured mice $(n=4)$. ${ }^{\#} P<0.05$, sLRP- $\alpha$-treated compared with vehicle-treated animals on the indicated day $(n=4)$. (C) TNF- $\alpha$ mRNA levels were determined by quantitative PCR in cultured primary Schwann cells after treatment with LPS, sLRP- $\alpha$, GST-RAP, or the indicated combinations thereof. Cells were pretreated with SLRP- $\alpha$ or SLRP- $\alpha$ and GST-RAP for 10 min prior to adding LPS for $4 \mathrm{~h}$. In some cases, the cells were washed after treatment with SLRP- $\alpha$ and prior to adding LPS. SLRP- $\alpha$ treatment caused a significant reduction in LPS-induced TNF- $\alpha$ expression by Schwann cells. ${ }^{*} P<0.05 ; n=5$.

of sLRP- $\alpha$ directly into the sciatic nerve prior to CCI blocked the increase in TNF- $\alpha$ mRNA expression in the spinal dorsal horn on days 1 and 5 . sLRP- $\alpha$ also significantly decreased IL- $1 \beta$ mRNA to below the presurgery level 1 day after CCI. Fairly high levels of IL-1 $\beta$ have been detected in naive spinal cord.

The increase in proinflammatory cytokine expression in the spinal cord following peripheral nerve injury most likely reflects the activity of spinal glia (56). Activation of ERK/MAPK in astrocytes may be important for sustained neuropathic pain (57). To test sLRP- $\alpha$ as a regulator of astrocytic ERK/MAPK activation, we established primary cultures of rat astrocytes, which were essentially homogenous as determined by immunofluorescence microscopy using an antibody specific for glial fibrillary acidic protein (GFAP) (Figure 8A). When the astrocytes were treated with TNF- $\alpha$ $(1 \mathrm{nM})$ for 10 minutes, ERK/MAPK activation was significantly increased, as determined by immunoblot analysis (Figure 8B). However, when the cells were treated with sLRP- $\alpha(50 \mathrm{nM})$ for 10 minutes prior to adding TNF- $\alpha$, the increase in activated ERK/ MAPK was blocked.

Microglial cell p38 MAPK is activated in inflammatory pain and after peripheral nerve injury and is thought to be associated with pain processing $(54,58)$. To test the effects of sLRP- $\alpha$ on P-p38 in microglia, we established primary cultures of these cells. The cultures were essentially homogenous, as determined by immunofluorescence microscopy using monoclonal antibody OX-42, which is specific for the complement receptor CR3 (Figure $8 \mathrm{C})$. When microglial cells were treated with TNF- $\alpha(1 \mathrm{nM})$ for 10 minutes, P-p38 was significantly increased, as determined by immunoblot analysis (Figure 8D); however, when the cells were treated with $50 \mathrm{nM}$ sLRP- $\alpha$ for 10 minutes prior to adding TNF- $\alpha$, the increase in P-p38 was blocked. sLRP- $\alpha$ alone did not independently regulate P-p38 in microglia. These studies demonstrate that sLRP- $\alpha$ is biologically active in the regulation of TNF- $\alpha$-initiated cell signaling in diverse glia.

\section{Discussion}

A shed form of LRP1, with an apparently intact $\alpha$-chain has been identified in human plasma (25). Similar forms of sLRP- $\alpha$ are present in a variety of mammalian, avian, and reptilian species (59). In all cases, the structure of sLRP- $\alpha$ appears similar; the intact $\alpha$-chain is associated with the $\mathrm{N}$-terminal portion of the $\beta$-chain, as might be anticipated if sLRP- $\alpha$ is formed by $\beta$-secretase-like enzymes (59). These enzymes are expressed in the PNS (24). 

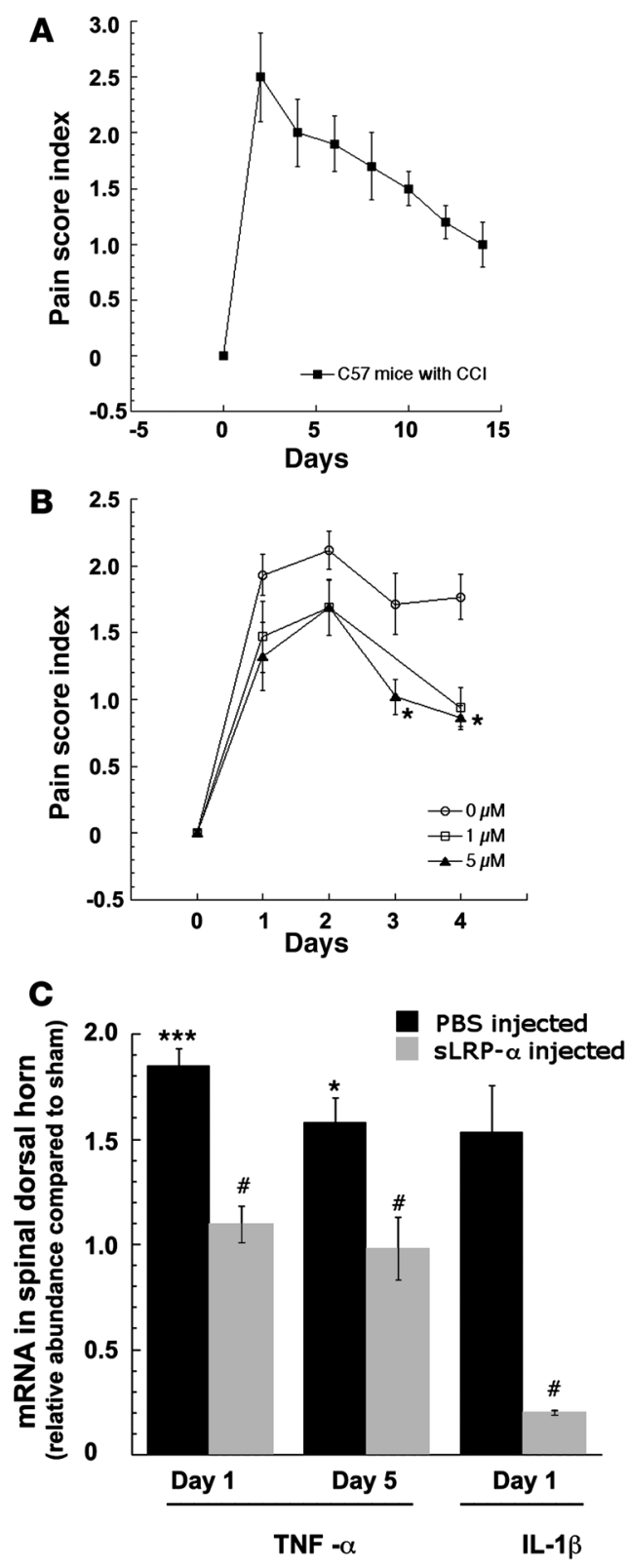

Other members of the LDL receptor family also undergo shedding. Megalin/LRP-2 is present in a soluble form in the urine (60), and a soluble fragment of the LDL receptor may be released from cell surfaces (61). However, the activity of shed forms of LDL receptor homologs remains unclear. Potential mechanisms by which shed receptors may regulate cell physiology include "loss of function" and expression of dominant-negative activity. The latter mechanism has been proposed to explain the activity of an engineered soluble form of LRP-5, which counteracts Wnt signaling when expressed by cells (62). Shed forms of LDL receptor homologs also may regulate the equilibrium of specific ligands, as has been recently demonstrated for $\beta$-amyloid peptide (63).

The results presented in this study demonstrate for what we believe to be the first time that SLRP- $\alpha$ regulates the inflammatory response that accompanies PNS injury. In the injured sciatic nerve, sLRP- $\alpha$ inhibits P-p38 and blocks expression of proinflammatory

\section{Figure 7}

SLRP- $\alpha$ regulates spontaneous pain-related behavior and antagonizes proinflammatory cytokine expression in the spinal dorsal horn. (A) Time course of spontaneous pain-related behavior scores in mice subjected to $\mathrm{CCl}$. (B) Spontaneous pain-related behavior scores in mice subjected to $\mathrm{CCl}$ and treated with SLRP- $\alpha(2 \mu \mathrm{l}$ of a $1-$ or $5-\mu \mathrm{M}$ solution, which is equal to 1 or $5 \mu \mathrm{g}$ ) or vehicle. ${ }^{\star} P<0.05$ compared with the vehicle-treated group. (C) Levels of TNF- $\alpha$ and IL-1 $\beta$ mRNA were determined by quantitative PCR in RNA extracts from the spinal dorsal horn, recovered 1 or 5 days following $\mathrm{CCl}$. Mice were injected with vehicle (PBS) or SLRP- $\alpha(5 \mu \mathrm{g})$ directly into the sciatic nerve prior to $\mathrm{CCl}$. The level of mRNA was standardized against that present in the uninjured (sham) spinal dorsal horn. ${ }^{* * *} P<0.001,{ }^{*} P<0.05$, mRNA levels in vehicle-treated animals before versus after $\mathrm{CCl}$. $n=4$ /group. sLRP- $\alpha$ treatment caused a significant reduction in mRNA level compared with vehicle treatment on the same day. ${ }^{\#} P<0.05 ; n=4$ /group.

cytokines. Because these biochemical changes are linked to neuropathic pain, it was not surprising that sLRP- $\alpha$ decreased spontaneous pain scores following CCI. We observed similar results in male mice, suggesting that estrous cycle over the short duration of behavioral testing was not a factor (data not shown). sLRP- $\alpha$ also decreased expression of TNF- $\alpha$ and IL- $1 \beta$ in the superficial dorsal horn, which is associated with neuropathic pain (55).

To explore the mechanism by which sLRP- $\alpha$ regulates the response to PNS injury, we studied cell signaling in cultured glia. In Schwann cells, astrocytes, and microglia, sLRP- $\alpha$ inhibited TNF- $\alpha$-initiated cell signaling to either p38 MAPK or ERK/ MAPK. Although these results may be explained by direct binding of TNF- $\alpha$ to sLRP- $\alpha$, we failed to demonstrate such an interaction. Furthermore, when Schwann cells were pretreated with sLRP- $\alpha$ and then washed to remove the remaining SLRP- $\alpha$ from solution, P-p38 in response to TNF- $\alpha$ and TNF- $\alpha$ mRNA expression in response to LPS were still inhibited. Thus it appears that sLRP- $\alpha$ preconditions or regulates Schwann cells so that the subsequent response to TNF- $\alpha$ is dampened.

Our model, in which sLRP- $\alpha$ preconditions cells so that the subsequent response to other mediators is altered, is best explained by direct binding of SLRP- $\alpha$ to a specific cell surface binding site. The inability of GST-RAP to inhibit the activity of sLRP- $\alpha$ argues against a second model in which sLRP- $\alpha$ rapidly depletes the medium of essential ligands for membrane-anchored LRP1 (a model based on dominant-negative activity). Because our cell signaling experiments were performed using cells that were pretreated with sLRP- $\alpha$ for 10 minutes, we treated cells under the equivalent conditions with FITC-labeled sLRP- $\alpha$ and demonstrated detectable binding by fluorescence microscopy. We complemented these studies with FACS experiments performed at $4^{\circ} \mathrm{C}$ and once again demonstrated sLRP- $\alpha$ binding to Schwann cells. Because the FACS experiments were performed at $4^{\circ} \mathrm{C}$, the binding detected represented cell surface-associated SLRP- $\alpha$.

We hypothesize that the binding of sLRP- $\alpha$ to Schwann cells may reflect more than 1 cell surface site, a subfraction of which (perhaps 1 site) is responsible for the bioactivity of sLRP- $\alpha$. In support of this hypothesis, we were not able to inhibit the binding of FITClabeled sLRP- $\alpha$ to Schwann cells with $250 \mathrm{nM}$ unlabeled sLRP- $\alpha$; experiments with higher concentrations of SLRP- $\alpha$ were precluded by availability of material and the tendency of SLRP- $\alpha$ to aggregate at high concentration (see below). In FACS experiments that are not shown, heparin partially inhibited binding of FITC-labeled 
A

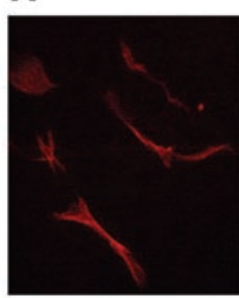

Anti-GFP

C

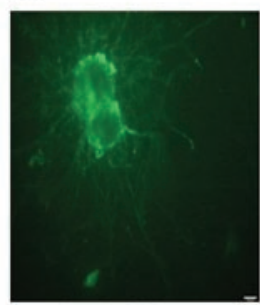

Anti-OX-42
Primary astrocytes

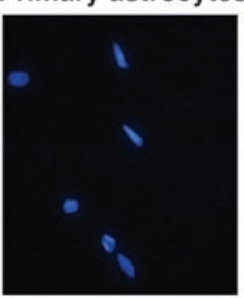

DAPI

Primary microglia

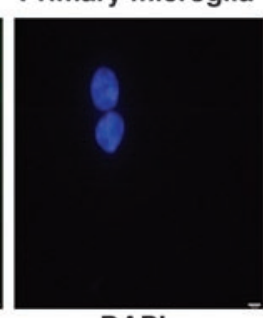

DAPI

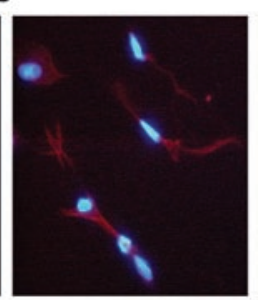

Anti-GFP + DAPI

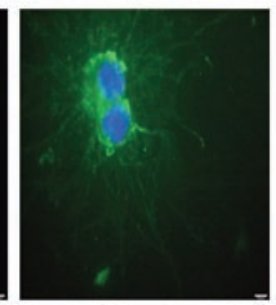

Anti-OX-42 + DAPI
B

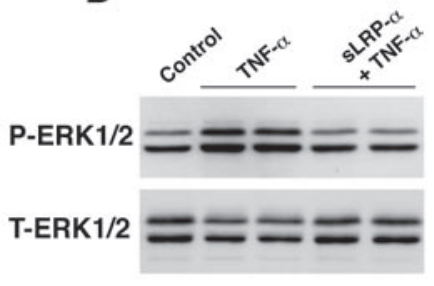

D

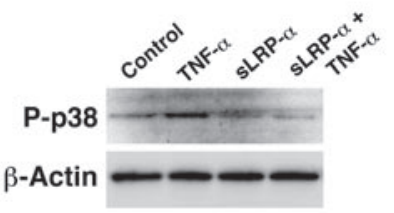

Figure 8

SLRP- $\alpha$ antagonizes TNF- $\alpha$-initiated cell signaling in astrocytes and microglia. (A) Astrocyte cultures are immunopositive for GFAP (anti-GFAP, red). Cell nuclei were stained with DAPI (blue). (B) Astrocytes were cultured in serum-free medium for $1 \mathrm{~h}$ to reduce the basal level of activation of ERK/MAPK. The cells were then treated with TNF- $\alpha(1 \mathrm{nM})$ or vehicle for $10 \mathrm{~min}$. Cell extracts were subjected to immunoblot analysis to detect P-ERK1/2 and T-ERK1/2. Some cells were pretreated with vehicle or SLRP- $\alpha$ (50 nM) for 10 min prior to adding TNF- $\alpha(1.0 \mathrm{nM})$ for $10 \mathrm{~min}$. The blot is representative of 2 independent studies. (C) Microglial cell cultures were immunopositive for the complement receptor CR3, as determined with antibody OX-42 (green). Cell nuclei were stained with DAPI (blue). (D) Microglia were pretreated with vehicle of sLRP- $\alpha$ for $10 \mathrm{~min}$ and then treated with TNF- $\alpha(1.0 \mathrm{nM})$. Extracts were subjected to immunoblot analysis to detect P-p38. $\beta$-Actin was used as a loading control.

sLRP- $\alpha$ to Schwann cells, consistent with the reported association of membrane-anchored LRP1 with heparin sulfate proteoglycans (64). However, the inhibition observed with heparin was incomplete. The inability of GST-RAP to block the interaction of sLRP- $\alpha$ with Schwann cells or the bioactivity of SLRP- $\alpha$ in experiments with TNF- $\alpha$ and LPS suggests that the clusters of complement-like repeats that are responsible for ligand binding are not involved in the cell surface interaction.

Because sLRP- $\alpha$ partially inhibited the binding of TNF- $\alpha$ to Schwann cells, a logical hypothesis may be that sLRP- $\alpha$ binds directly to TNF- $\alpha$ receptors. However, sLRP- $\alpha$ also inhibited the response to LPS, which is mediated by distinct receptors such as TLR4 (65). Identifying the specific cell surface binding site for sLRP- $\alpha$, which is responsible for its cell-regulatory activity, is clearly an important next step. There is precedent for soluble forms of cellular receptors as direct regulators of cell physiology. The soluble form of the urokinase receptor, uPAR, regulates activation of ERK/MAPK and thereby controls cell growth and cell migration (66).

The activities of purified sLRP- $\alpha$ demonstrated here do not discount the possibility that significant shedding of LRP1 in vivo also may regulate cell physiology by loss of function of the membraneanchored receptor $(59,67)$. In the PNS, shedding may adversely affect Schwann cell survival because membrane-anchored LRP1 controls the activity of PI3K and caspase activation in response to stress (20). A role for LRP1 in neuronal cell survival also has been recently demonstrated (68). The rapid association of sLRP- $\alpha$ with Schwann cells demonstrated in vitro may be reflected in our immunohistochemistry studies with $\alpha$-chain-specific antibody. In response to injury, Schwann cells upregulate LRP1 mRNA expression (20); however, the intense LRP1 $\alpha$-chain immunoreactivity observed in Schwann cells in vivo following injury may reflect both membrane-anchored and shed LRP1. The latter form may be released from Schwann cells, axons, or other endoneural cells and then reassociate with the Schwann cell surface.

In the course of these studies, we purified multiple preparations of sLRP- $\alpha$ from human plasma. At high concentration, sLRP- $\alpha$ demonstrated a tendency to aggregate, which was associated with loss of biological activity. We think that this process may explain why GST-RAP promoted sLRP- $\alpha$ binding to Schwann cells and, in some studies, increased the biological activity of sLRP- $\alpha$. We hypothesize that RAP counteracts sLRP- $\alpha$ aggregation. Because, in contrast with the membrane-anchored form of LRP1, the biological activity of sLRP- $\alpha$ does not depend on the clusters of complement-like repeats that are blocked by RAP, this protein may in fact enhance sLRP- $\alpha$ activity. The effects of RAP on SLRP- $\alpha$ aggregation are currently under investigation.

Proinflammatory cytokines produced in PNS injury represent major targets for chronic pain management. TNF- $\alpha$ in particular has been shown to be a key regulator of cellular changes in the injured nerve that lead to neuropathic pain $(35,54)$. Our results suggest that SLRP- $\alpha$ or fragments thereof may have therapeutic activity. Whether naturally produced sLRP- $\alpha$ regulates pain following nerve injury probably depends on the amount generated. Our hypothesis that significant amounts of sLRP- $\alpha$ are produced in the injured sciatic nerve is based on our immunoblot data showing that LRP1 $\alpha$-chain increases in injury, whereas the $\beta$-chain decreases. To explain these immunoblot results, shedding would have to be accompanied by destabilization of the $\beta$-chain. Because RAP did not antagonize sLRP- $\alpha$, RAP may represent an interesting reagent to distinguish between the activities of membrane-anchored and shed LRP1 in vivo. The overall activity of LRP1 in the PNS may reflect the integrated activities of both forms of the protein.

\section{Methods}

Antibodies and reagents. Taqman primers and probes for rat cyclophilin were synthesized by Biosearch Technologies and have been have been previously described $(69,70)$. Primers and probes for mouse TNF- $\alpha$, rat TNF- $\alpha$, IL-1 $\beta$, and GAPDH were purchased from Applied BioSystems. Antibodies specific for tubulin and $\beta$-actin were purchased from SigmaAldrich. Polyclonal antibody that recognizes the axoplasm marker, PGP9.5, and monoclonal antibody specific for GFAP were purchased from Chemicon. CR3-specific monoclonal antibody OX-42 was purchased 
from Serotec. Rabbit polyclonal antibodies specific for phosphorylated p38 MAPK, total p38 MAPK, phosphorylated ERK/MAPK, and total ERK/ MAPK were purchased from Cell Signaling Technologies. Monoclonal antibody $11 \mathrm{H} 4$, which recognizes the $85-\mathrm{kDa}$ LRP1 $\beta$-chain, was purified from hybridoma cells, available from the ATCC. Rabbit polyclonal LRP1 $\alpha$-chain-specific antibody 2629 was a kind gift from Dudley Strickland (University of Maryland School of Medicine, Baltimore, Maryland, USA). This antibody has been previously characterized (71). Recombinant rat TNF- $\alpha$ and PDGF were from R\&D Systems. Recombinant human erythropoietin (rhEpo) was purchased from Johnson \& Johnson. GST-RAP was prepared and purified as previously described (72). As a control, we expressed GST in bacteria transformed with the empty vector PGEX-2T. Purified GST and GST-RAP were subjected to chromatography to remove endotoxin, according to the manufacturer's instructions (Pierce Biotechnology). GST-specific antibody coupled to horseradish peroxidase was from GE Healthcare.

Affinity purification of sLRP- $\alpha$ from human plasma. An affinity matrix was prepared by coupling $10 \mathrm{mg}$ of GST-RAP to $2 \mathrm{ml}$ of NHS-activated Sepharose 4 Fast Flow (GE Healthcare), according to the manufacturer's instructions. Fresh-frozen human plasma, containing a mixture of protease inhibitors and $5 \mathrm{mM} \mathrm{CaCl}_{2}$, was thawed at $37^{\circ} \mathrm{C}$ and dialyzed against 50 $\mathrm{mM}$ Tris, $150 \mathrm{mM} \mathrm{NaCl}, \mathrm{pH} 7.5$, with $1 \mathrm{mM} \mathrm{CaCl}_{2}$ for $12 \mathrm{~h}$ at $4^{\circ} \mathrm{C}$. The dialyzed plasma was subjected to centrifugation at $13,000 \mathrm{~g}$ for $15 \mathrm{~min}$ at $4^{\circ} \mathrm{C}$, filtered through a $0.22-\mu \mathrm{m}$ filter, and then incubated with GSTRAP Sepharose for $12 \mathrm{~h}$ at $4^{\circ} \mathrm{C}$. The beads were washed and packed into a column. RAPs were eluted with $0.1 \mathrm{M}$ sodium acetate, $0.5 \mathrm{M} \mathrm{NaCl}, \mathrm{pH} 4$. Eluted fractions were neutralized by rapid mixing with $50 \mathrm{mM}$ Tris- $\mathrm{HCl}$, $\mathrm{pH}$ 8. To detect sLRP- $\alpha$, fractions were screened by immunoblot analysis with $\alpha$-chain-specific polyclonal antibody. Positive fractions were pooled and dialyzed against $20 \mathrm{mM}$ sodium phosphate, $150 \mathrm{mM} \mathrm{NaCl}, \mathrm{pH} 7.4$, containing $0.5 \mathrm{mM} \mathrm{CaCl}_{2}$ at $4{ }^{\circ} \mathrm{C}$. Purity of the sLRP- $\alpha$ was determined by SDS-PAGE and Coomassie staining.

Purification of the sLRP- $\alpha-R A P$ complex. SLRP- $\alpha$ was incubated with an 8 -fold molar excess of endotoxin-free GST-RAP for $30 \mathrm{~min}$ at $37^{\circ} \mathrm{C}$. The sLRP- $\alpha$-GST-RAP complex was purified from unbound GST-RAP by molecular exclusion chromatography on Ultrogel Aca-22 (Pall Life Sciences). To detect SLRP- $\alpha$, fractions were screened by immunoblot analysis using $\alpha$-chain-specific antibody. To detect GST-RAP, fractions were screened by immunoblot analysis using GST-specific antibody. For some experiments SLRP- $\alpha$ was incubated with a 2 -fold molar excess of GST-RAP for $30 \mathrm{~min}$ at $37^{\circ} \mathrm{C}$, and the resulting sLRP- $\alpha-$ GST-RAP complex was used without further purification.

Nerve injury model systems. Adult female Sprague-Dawley rats (250 g) and C57BL/6J mice were housed in pairs with a 12-hour light/12-hour dark cycle and given ad libitum access to food and water. Adult rats and mice were anesthetized with $4 \%$ isoflurane (IsoSol; VedCo) and were sacrificed by transcardial injection of Euthasol (Virbac Corp.). For harvesting tissue, animals were euthanized by administration of nembutal $(50 \mathrm{mg} / \mathrm{ml})$, diazepam $(5 \mathrm{mg} / \mathrm{ml})$ and $0.9 \%$ saline in a 1:1:2 formulation. All procedures were performed according to protocols approved by the University of California, San Diego, and the VA Healthcare System Committee on Animal Research and conformed to NIH Guidelines for Animal Care and Experimentation.

Sciatic nerve crush injury experiments were performed in adult rats. The left sciatic nerve was exposed at the sciatic nerve notch and crushed twice for $5 \mathrm{~s}$ using flat forceps, as described previously (41). The surgical site was repaired and animals were allowed to fully regain consciousness. Nerve tissue distal to the injury site $(0.5 \mathrm{~cm})$ was collected at 0,1 , and 3 days after injury. Uninjured nerve was collected from control animals that underwent sham operation. As a second control, the uninjured contralateral sciatic nerve was harvested as well.
CCI experiments were performed in mice. The sciatic nerve was exposed unilaterally at the mid-thigh level. Three 10-0 Prolene ligatures (Ethicon) were placed around the nerve with $1-\mathrm{mm}$ spacing. A 5 -mm section of 4-0 chromic gut was placed parallel and adjacent to the injury site on the sciatic nerve. The ligatures were tied until they just slightly constricted the diameter of the nerve, and a brief foot-twitch was visualized by the surgeon (36). In some experiments, $2 \mu \mathrm{l}$ of sLRP- $\alpha$ or vehicle were injected directly into the CCI site immediately before tightening the ligatures. The muscle layer was closed using silk suture, and the skin was closed using small surgical staples. The mice were allowed to recover from anesthesia. Nerve tissue was harvested from the CCI site and extending $2 \mathrm{~mm}$ below the site while the mice were under anesthesia. Tissue from the spinal dorsal horn, representing the lumbar enlargement (L4-L6), also was collected. As a control, mice were subjected to sham operation and naive nerve tissue was collected.

Primary cell cultures. Schwann cells were isolated from sciatic nerves of 1-day-old Sprague Dawley rats as previously described $(43,73)$ and further selected from fibroblasts using anti-fibronectin antibody and rabbit complement. This method yielded Schwann cell cultures that were about 99\% pure, as assessed by immunofluorescence microscopy for S100, a specific marker of Schwann cells. Primary Schwann cells were maintained in DMEM containing $10 \% \mathrm{FBS}, 100 \mathrm{U} / \mathrm{ml}$ penicillin, $100 \mu \mathrm{g} / \mathrm{ml}$ streptomycin, $21 \mu \mathrm{g} / \mathrm{ml}$ bovine pituitary extract, and $4 \mu \mathrm{M}$ forskolin (complete medium) at $37^{\circ} \mathrm{C}$ under humidified $5.0 \% \mathrm{CO}_{2}$. Schwann cell cultures were passaged no more than 4 times before conducting experiments.

Rat astrocyte- and microglia-enriched cultures were prepared as previously described (74). Briefly, brains were harvested from euthanized 1-dayold rat pups. The hindbrain, blood vessels, and meninges were removed. The remaining tissue was dissociated by mild mechanical trituration in sterile calcium- and magnesium-free chilled W3 buffer (145 mM NaCl, $5.4 \mathrm{mM}$ $\mathrm{KCl}, 1 \mathrm{mM} \mathrm{NaH} \mathrm{PO}_{4}, 15 \mathrm{mM}$ HEPES, and $11 \mathrm{mM}$ glucose; $\mathrm{pH}$ 7.4). Cells $\left(2.5 \times 10^{7}\right)$ were then seeded on PDL-coated $75 \mathrm{~cm}^{2}$ flasks in DMEM/F12 nutrient mixture (1:1) supplemented with $10 \%$ heat-inactivated FBS, $2 \mathrm{mM}$ L-glutamine, $1 \mathrm{mM}$ sodium pyruvate, $100 \mu \mathrm{M}$ nonessential amino acids, 50 $\mathrm{U} / \mathrm{mL}$ penicillin, and $50 \mu \mathrm{g} / \mathrm{ml}$ streptomycin. These cultures are maintained at $37^{\circ} \mathrm{C}$ with $5 \% \mathrm{CO}_{2}$. Medium was replaced at 1 and 4 days after plating and every 3 days thereafter. When the cultures were confluent (typically at 14 days), microglia were separated by agitation (180 rpm for $5 \mathrm{~h}$ ) and the essentially homogenous astrocytes were retained. Astrocyte cultures were more than $95 \%$ homogenous as determined by immunostaining for GFAP. Microglial cell homogeneity was determined with antibody OX-42.

Immunoblotting and RAP ligand blotting. Protein extracts were prepared from cell cultures or nerve tissue, as previously described (75). Equal amounts of cellular protein $(35-50 \mu \mathrm{g})$ were subjected to SDS-PAGE using the Laemmli buffer system (76) and electrotransferred to polyvinylidene fluoride (PVDF) membranes (Bio-Rad). Proteins were visualized using $0.2 \%$ Ponceau Red prior to immunoblotting. Membranes were blocked with 5\% nonfat dry milk in $20 \mathrm{mM}$ Tris- $\mathrm{HCl}, 150 \mathrm{mM} \mathrm{NaCl}$, pH 7.4, 0.1\% Tween 20 (TBST). Primary antibodies were diluted in TBS containing $0.1 \%$ BSA and incubated with blocked membranes. This was followed by horseradish peroxidase-conjugated secondary antibodies that were diluted in 5\% nonfat milk. Detection was performed using Western Lightning horseradish peroxidase chemiluminescence (Perkin-Elmer) and Kodak Biomaxlight Films. For RAP ligand blotting, blocked membranes were incubated with GST-RAP $(0.1 \mu \mathrm{M})$ for $1 \mathrm{~h}$ at $20^{\circ} \mathrm{C}$ and then GST-specific antibody coupled to horseradish peroxidase.

Immunohistochemistry. Heavily anesthetized animals were perfused with fresh $4 \%$ paraformaldehyde in $0.2 \mathrm{M}$ sodium phosphate, $\mathrm{pH}$ 7.4. Tissues were harvested, postfixed overnight in perfusate, and processed for paraffin embedding $(70,77)$. Paraffin sections $(10 \mu \mathrm{m})$ were cut, deparaffinized, and incubated in antigen retrieval (Dako) for $5 \mathrm{~min}$ at $95^{\circ} \mathrm{C}$ and then for 20 
min at room temperature. The sections were then treated in 3\% hydrogen peroxide for $5 \mathrm{~min}$. Nonspecific antibody binding was blocked with $10 \%$ normal goat serum. Sections were treated with primary antibody overnight at $4^{\circ} \mathrm{C}$ in $0.1 \%$ goat serum in PBS, rinsed, and subsequently incubated for $1 \mathrm{~h}$ with biotinylated HRP-conjugated goat anti-rabbit secondary antibody, followed by Avidin Biotin complex (ABC). Sections were developed with 3'3-diaminobenzidine and counterstained with methyl green. Some sections were treated only with secondary antibody as a control. Imaging was done using a Leica microscope and Open Lab software.

Labeling of sLRP- $\alpha$ and binding to Schwann cells. SLRP- $\alpha$ was labeled by incubation with a 10 -fold molar excess of NHS-fluorescein (Pierce Biotechnology) for $15 \mathrm{~min}$ at $20^{\circ} \mathrm{C}$. Free dye was eliminated by extensive dialysis against $20 \mathrm{mM}$ sodium phosphate, $150 \mathrm{mM} \mathrm{NaCl}$, pH 7.4, containing $0.5 \mathrm{mM} \mathrm{CaCl}_{2}$.

For fluorescence microscopy studies, Schwann cells were cultured on poly-D-lysine-coated glass chamber slides for $24 \mathrm{~h}$ in serum-containing medium. The cells were washed and then incubated with FITC-labeled sLRP- $\alpha(50 \mathrm{nM})$ for $10 \mathrm{~min}$ at $37^{\circ} \mathrm{C}$ in $0.5 \%$ FBS containing medium. After further washing, the cells were fixed in paraformaldehyde ( $4 \%$ in PBS) for 10 min but were not permeabilized. The coverslips were mounted in Prolong gold mounting medium containing the nuclear stain, DAPI (Invitrogen).

For FACS experiments, FITC-labeled sLRP- $\alpha(50 \mathrm{nM})$ was incubated with $10^{5}$ cells for $1 \mathrm{~h}$ at $4^{\circ} \mathrm{C}$. FITC-labeled IgG specific for the GFP (Invitrogen) was used as a control. The cells were then washed 2 times and subjected to FACS to detect cell-associated FITC-labeled sLRP- $\alpha$. FACS was performed using the BD FACSCanto II flow cytometer (BD Biosciences). Data were analyzed using FlowJo software (Tree Star).

FACS analysis of TNF- $\alpha$ binding to Schwann cells. Binding of recombinant human TNF- $\alpha$ to Schwann cells was determined using the Fluorokine kit (R\&D Systems). Schwann cells were dissociated using trypsin for $5 \mathrm{~min}$ at $22^{\circ} \mathrm{C}$. The trypsin was neutralized with complete growth media. The cells were centrifuged for $5 \mathrm{~min}$ at $1,000 \mathrm{~g}$, washed 2 times with $20 \mathrm{mM}$ sodium phosphate, $150 \mathrm{mM} \mathrm{NaCl}$, pH 7.4, containing $0.5 \mathrm{mM} \mathrm{CaCl}_{2}$ and $0.5 \mathrm{mM}$ $\mathrm{MgCl}_{2}\left(\mathrm{PBS}+\mathrm{Ca} / \mathrm{Mg}\right.$ ) and resuspended in PBS $+\mathrm{Ca} / \mathrm{Mg}$ at $4 \times 10^{6} \mathrm{cells} / \mathrm{ml}$. Some cells were treated with sLRP- $\alpha(50 \mathrm{nM})$ for $15 \mathrm{~min}$ at $22^{\circ} \mathrm{C}$ and then chilled on ice for $10 \mathrm{~min}$. Biotinylated TNF- $\alpha$ was then incubated with $10^{5}$ cells for $1 \mathrm{~h}$ at $4^{\circ} \mathrm{C}$. As a control, cells were incubated with SBTI. After washing, FITC-labeled streptavidin was added for an additional $30 \mathrm{~min}$ at $4^{\circ} \mathrm{C}$. The cells were then washed 2 times and subjected to FACS.

RNA isolation and Taqman real-time quantitative PCR. DNA-free total RNA was extracted from nerve tissue and cells in culture using TrizoL, as directed by the manufacturer (Invitrogen). Samples were purified and treated with DNase. cDNA was synthesized using the ProSTAR first-strand RT-PCR kit (Stratagene). Expression of target genes, including TNF- $\alpha$ and IL-1 $\beta$, was measured by quantitative PCR (MX4000; Stratagene) using a 1-step program: $95^{\circ} \mathrm{C}$ for $10 \mathrm{~min}, 95^{\circ} \mathrm{C}$ for $30 \mathrm{~s}$, and $60^{\circ} \mathrm{C}$ for $1 \mathrm{~min}$ for 40 cycles. Mouse GAPDH or rat cyclophilin mRNA was measured as the normalizer. Samples without cDNA were analyzed as "no template" controls. Samples were also studied without prior treatment with reverse transcrip- tase to confirm the absence of contamination with genomic DNA. mRNA levels were quantitated by the comparative threshold cycle $(\mathrm{Ct})$ method (78). Ct values for each target gene were normalized against the $\mathrm{Ct}$ value for the housekeeping gene. The calibrator group (sham or unstimulated cells) was used to determine relative abundance. Data analysis was accomplished using software associated with the Stratagene MX4000, as previously described (79).

Scoring spontaneous pain. Wild-type mice (C57BL/6J; $n=5$ /group) were subjected to CCI, placed in plexiglass cylinders $(19 \times 31 \mathrm{~cm})$, and allowed to habituate. Baseline response measurements were determined for each animal prior to testing. One animal at a time was continuously observed for $2 \mathrm{~min}$. This was repeated 2 more times within the next $2 \mathrm{~h}$. Various positions of the injured hind paw were continuously observed and rated according to the following numerical scoring system: 0 , paw placed normally on the floor; 1 , paw placed lightly on the floor and toes ventroflexed; 2, only internal edge of the paw contacted the floor; 3 , contact restricted to the heel; 4 , total paw elevation. During each 2-minute observation period, scoring was done at 5 -s intervals by an investigator who was blinded to the experimental groupings. The spontaneous pain index for each observation period was calculated by multiplying the interval number by the interval score and dividing by the total number of intervals ( 25 in all/session) (80). The overall pain index for each mouse on each day was obtained by averaging the scores obtained during the 3 observation periods. In general, the 3 scores obtained on a single day with 1 mouse varied by less than $20 \%$ relative to the mean. Results at each day are presented as the mean \pm SD for the cohort.

Statistics. In cell culture experiments, replicates always refer to separate experiments typically performed with internal duplicates. Animal model experiments were performed using coded animal numbers to avoid observer bias. Data from quantitative PCR studies and densitometry were subjected to ANOVA analysis. Tukey's post hoc analysis was used to assess differences between treatment groups. For pain data, nonparametric analysis using a Kruskal-Wallis test was used to compare treatment means on day 3 or 4 . Differences in values obtained for a single cohort over time and between different cohorts were assessed by a Friedman test.

\section{Acknowledgments}

This work was supported by NIH grants R01 NS-41983 (to W.M. Campana), R01 HL-60551 (to S.L. Gonias), and R01 NS018715 (to R.R. Myers).

Received for publication April 11, 2007, and accepted in revised form October 3, 2007.

Address correspondence to: W. Marie Campana, Department of Anesthesiology (0629), University of California, San Diego, 9500 Gilman Drive, MTF 445, La Jolla, California 92093-0629, USA. Phone: (858) 822-3767; Fax: (858) 534-1445; E-mail: wcampana@ucsd.edu.
1. Herz, J., and Strickland, D.K. 2001. LRP: a multifunctional scavenger and signaling receptor. J. Clin. Invest. 108:779-784.

2. Houston, D.W., and Wylie, C. 2002. Cloning and expression of Xenopus Lrp5 and Lrp6 genes. Mech. Dev. 117:337-342.

3. Wehrli, M., et al. 2000. Arrow encodes an LDLreceptor-related protein essential for Wingless signalling. Nature. 407:527-530.

4. Yochem, J., and Greenwald, I. 1993. A gene for a low density lipoprotein receptor-related protein in the nematode Caenorhabditis elegans. Proc. Natl. Acad. Sci.U.S. A. 90:4572-4576.
5. Pinson, K.I., Brennan, J., Monkley, S., Avery, B.J., and Skarnes, W.C. 2000. An LDL-receptor-related protein mediates Wnt signalling in mice. Nature. 407:535-538.

6. Trommsdorff, M., et al. 1999. Reeler/Disabled-like disruption of neuronal migration in knockout mice lacking the VLDL receptor and ApoE receptor 2. Cell. 97:689-701.

7. Boucher, P., Gotthardt, M., Li, W.P., Anderson, R.G., and Herz, J. 2003. LRP: role in vascular wall integrity and protection from atherosclerosis. Science. 300:329-332.

8. Li, Y., Lu, W., He, X., Schwartz, A.L., and Bu, G.
2004. LRP6 expression promotes cancer cell proliferation and tumorigenesis by altering beta-catenin subcellular distribution. Oncogene. 23:9129-9135.

9. Zerbinatti, C.V., and Bu, G. 2005. LRP and Alzheimer's disease. Rev. Neurosci. 16:123-135.

10. Willnow, T.E., Moehring, J.M., Inocencio, N.M., Moehring, T.J., and Herz, J. 1996. The low-density-lipoprotein receptor-related protein (LRP) is processed by furin in vivo and in vitro. Biochem. J. 313:71-76.

11. Strickland, D.K., Gonias, S.L., and Argraves, W.S. 2002. Diverse roles for the LDL receptor family. Trends Endocrinol. Metab. 13:66-74. 
12. Gotthardt, M., et al. 2000. Interactions of the low density lipoprotein receptor gene family with cytosolic adaptor and scaffold proteins suggest diverse biological functions in cellular communication and signal transduction. J. Biol. Chem. 275:25616-25624.

13. Kinoshita, A., et al. 2001. Demonstration by fluorescence resonance energy transfer of two sites of interaction between the low-density lipoprotein receptor-related protein and the amyloid precursor protein: role of the intracellular adapter protein Fe65. J. Neurosci. 21:8354-8361.

14. Su, H.P., et al. 2002. Interaction of CED-6/GULP, an adapter protein involved in engulfment of apoptotic cells with CED-1 and CD91/low density lipoprotein receptor-related protein (LRP). J. Biol. Chem. 277:11772-11779.

15. Gonias, S.L., Wu, L., and Salicioni, A.M. 2004. Low density lipoprotein receptor-related protein: regulation of the plasma membrane proteome. Thromb. Haemost. 91:1056-1064.

16. Gaultier, A., Salicioni, A.M., Arandjelovic, S., and Gonias, S.L. 2006. Regulation of the composition of the extracellular matrix by low density lipoprotein receptor-related protein-1. J. Biol. Chem. 281:7332-7340.

17. Polavarapu, R., et al. 2007. Tissue-type plasminogen activator-mediated shedding of astrocytic low-density lipoprotein receptor-related protein increases the permeability of the neurovascular unit. Blood. 109:3270-3278.

18. Yepes, M., et al. 2003. Tissue-type plasminogen activator induces opening of the blood-brain barrier via the LDL receptor-related protein. J. Clin. Invest. 112:1533-1540.

19. Shibata, M., et al. 2000. Clearance of Alzheimer's amyloid-ss(1-40) peptide from brain by LDL receptor-related protein-1 at the blood-brain barrier. J. Clin. Invest. 106:1489-1499.

20. Campana, W.M., et al. 2006. The low-density lipoprotein receptor-related protein is a pro-survival receptor in Schwann cells: possible implications in peripheral nerve injury. J. Neurosci. 26:11197-11207.

21. Rozanov, D.V., Hahn-Dantona, E., Strickland, D.K., and Strongin, A.Y. 2004. The low density lipoprotein receptor-related protein LRP is regulated by membrane type-1 matrix metalloproteinase (MT1MMP) proteolysis in malignant cells. J. Biol. Chem. 279:4260-4268.

22. May, P., Reddy, Y.K., and Herz, J. 2002. Proteolytic processing of low density lipoprotein receptor-related protein mediates regulated release of its intracellular domain. J. Biol. Chem. 277:18736-18743.

23. von Arnim, C.A., et al. 2005. The low density lipoprotein receptor-related protein (LRP) is a novel beta-secretase (BACE1) substrate. J. Biol. Chem. 280:17777-17785.

24. Hu, X., et al. 2006. Bace1 modulates myelination in the central and peripheral nervous system. Nat. Neurosci. 9:1520-1525.

25. Quinn, K.A., et al. 1997. Soluble low density lipoprotein receptor-related protein (LRP) circulates in human plasma. J. Biol. Chem. 272:23946-23951.

26. Shamash, S., Reichert, F., and Rotshenker, S. 2002. The cytokine network of Wallerian degeneration: tumor necrosis factor-alpha, interleukin-1alpha, and interleukin-1beta. J. Neurosci. 22:3052-3060.

27. Stoll, G., Jander, S., and Myers, R.R. 2002. Degeneration and regeneration of the peripheral nervous system: from Augustus Waller's observations to neuroinflammation. J. Peripher. Nerv. Syst. 7:13-27.

28. Myers, R.R., Campana, W.M., and Shubayev, V.I. 2006. The role of neuroinflammation in neuropathic pain: mechanisms and therapeutic targets. Drug Discov. Today. 11:8-20.

29. Hashizume, H., DeLeo, J.A., Colburn, R.W., and Weinstein, J.N. 2000. Spinal glial activation and cytokine expression after lumbar root injury in the rat. Spine. 25:1206-1217.

30. Takahashi, N., Kikuchi, S., Shubayev, V.I., Campana, W.M., and Myers, R.R. 2006. TNF-alpha and phosphorylation of ERK in DRG and spinal cord: insights into mechanisms of sciatica. Spine. 31:523-529.

31. Jin, X., and Gereau, R.W. 2006. Acute p38-mediated modulation of tetrodotoxin-resistant sodium channels in mouse sensory neurons by tumor necrosis factor-alpha. J. Neurosci. 26:246-255.

32. Schafers, M., Brinkhoff, J., Neukirchen, S., Marziniak, M., and Sommer, C. 2001. Combined epineurial therapy with neutralizing antibodies to tumor necrosis factor-alpha and interleukin-1 receptor has an additive effect in reducing neuropathic pain in mice. Neurosci. Lett. 310:113-116.

33. Sorkin, L.S., Xiao, W.H., Wagner, R., and Myers, R.R. 1997. Tumour necrosis factor-alpha induces ectopic activity in noceiceptive primary afferent fibres. Neuroscience. 81:255-262.

34. Wagner, R., Myers, R.R., and O’Brien, J.S. 1998. Prosaptide prevents hyperalgesia and reduces peripheral TNFR1 expression following TNF-alpha nerve injection. Neuroreport. 9:2827-2831.

35. Wagner, R., and Myers, R.R. 1996. Endoneurial injection of TNF-alpha produces neuropathic pain behaviors. Neuroreport. 7:2897-2901.

36. Bennett, G.J., and Xie, Y.K. 1988. A peripheral mononeuropathy in rat that produces disorders of pain sensation like those seen in man. Pain. 33:87-107.

37. Wu, L., Arandjelovic, S., and Gonias, S.L. 2004. Effects of low density lipoprotein receptor-related protein-1 on the expression of platelet-derived growth factor beta-receptor in vitro. J. Cell Biochem. 93:1169-1177.

38. Medh, J.D., et al. 1995. The 39-kDa receptor-associated protein modulates lipoprotein catabolism by binding to LDL receptors. J. Biol. Chem. 270:536-540.

39. Williams, S.E., Ashcom, J.D., Argraves, W.S., and Strickland, D.K. 1992. A novel mechanism for controlling the activity of alpha 2-macroglobulin receptor/low density lipoprotein receptor-related protein. Multiple regulatory sites for 39-kDa receptor-associated protein. J. Biol. Chem. 267:9035-9040.

40. Quinn, K.A., Pye, V.J., Dai, Y.P., Chesterman, C.N., and Owensby, D.A. 1999. Characterization of the soluble form of the low density lipoprotein receptorrelated protein (LRP). Exp. Cell Res. 251:433-441.

41. Myers, R.R., et al. 2003. Inhibition of p38 MAP kinase activity enhances axonal regeneration. Exp. Neurol. 184:606-614.

42. Chandross, K.J., et al. 1996. TNF alpha inhibits Schwann cell proliferation, connexin 46 expression, and gap junctional communication. Mol. Cell. Neurosci. 7:479-500.

43. Campana, W.M., Hiraiwa, M., and O'Brien, J.S. 1998. Prosaptide activates the MAPK pathway by a G-protein-dependent mechanism essential for enhanced sulfatide synthesis by Schwann cells. FASEB J. 12:307-314.

44. Jessen, K.R., Morgan, L., Stewart, H.J., and Mirsky, R. 1990. Three markers of adult non-myelin-forming Schwann cells, 217c(Ran-1), A5E3 and GFAP: development and regulation by neuron-Schwann cell interactions. Development. 109:91-103.

45. Wajant, H., Pfizenmaier, K., and Scheurich, P. 2003. Tumor necrosis factor signaling. Cell Death Differ. 10:45-65.

46. Baldassare, J.J., Bi, Y., and Bellone, C.J. 1999. The role of p38 mitogen-activated protein kinase in IL-1 beta transcription. J. Immunol. 162:5367-5373.

47. Thirunavukkarasu, C., Watkins, S.C., and Gandhi, C.R. 2006. Mechanisms of endotoxin-induced NO, IL-6, and TNF-alpha production in activated rat hepatic stellate cells: role of p38 MAPK. Hepatology. 44:389-398.

48. Asbury, A.K., and Johnson, P.C. 1978. Pathology of peripheral nerve. Major Probl. Pathol. 9:1-311.

49. Kleinschnitz, C., Brinkhoff, J., Zelenka, M., Sommer, C., and Stoll, G. 2004. The extent of cytokine induction in peripheral nerve lesions depends on the mode of injury and NMDA receptor signaling. J. Neuroimmunol. 149:77-83.

50. Skundric, D.S., Bealmear, B., and Lisak, R.P. 1997. Induced upregulation of IL-1, IL-1RA and IL-1R type I gene expression by Schwann cells. J. Neuroimmunol. 74:9-18.

51. Campana, W.M., et al. 2006. Erythropoietin reduces Schwann cell TNF-alpha, Wallerian degeneration and pain-related behaviors after peripheral nerve injury. Eur. J. Neurosci. 23:617-626.

52. Netea, M.G., et al. 1996. Low-density lipoprotein receptor-deficient mice are protected against lethal endotoxemia and severe gram-negative infections. J. Clin. Invest. 97:1366-1372.

53. Raghavendra, V., Tanga, F.Y., and DeLeo, J.A. 2004. Complete Freunds adjuvant-induced peripheral inflammation evokes glial activation and proinflammatory cytokine expression in the CNS. Eur. J. Neurosci. 20:467-473.

54. Schafers, M., Svensson, C.I., Sommer, C., and Sorkin, L.S. 2003. Tumor necrosis factor-alpha induces mechanical allodynia after spinal nerve ligation by activation of $\mathrm{p} 38$ MAPK in primary sensory neurons. J. Neurosci. 23:2517-2521.

55. Raghavendra, V., Rutkowski, M.D., and DeLeo, J.A. 2002. The role of spinal neuroimmune activation in morphine tolerance/hyperalgesia in neuropathic and sham-operated rats. J. Neurosci. 22:9980-9989.

56. Milligan, E.D., et al. 2003. Spinal glia and proinflammatory cytokines mediate mirror-image neuropathic pain in rats. J. Neurosci. 23:1026-1040.

57. Ma, W., and Quirion, R. 2005. The ERK/MAPK pathway, as a target for the treatment of neuropathic pain. Expert Opin. Ther. Targets. 9:699-713.

58. Svensson, C.I., et al. 2003. Activation of p38 mitogen-activated protein kinase in spinal microglia is a critical link in inflammation-induced spinal pain processing. J. Neurochem. 86:1534-1544.

59. Grimsley, P.G., Quinn, K.A., Chesterman, C.N., and Owensby, D.A. 1999. Evolutionary conservation of circulating soluble low density lipoprotein receptor-related protein-like ("LRP-like") molecules. Thromb. Res. 94:153-164.

60. Kounnas, M.Z., Church, F.C., Argraves, W.S., and Strickland, D.K. 1996. Cellular internalization and degradation of antithrombin III-thrombin, heparin cofactor II-thrombin, and alpha 1-antitrypsintrypsin complexes is mediated by the low density lipoprotein receptor-related protein. J. Biol. Chem. 271:6523-6529.

61. Fischer, D.G., Tal, N., Novick, D., Barak, S., and Rubinstein, M. 1993. An antiviral soluble form of the LDL receptor induced by interferon. Science. 262:250-253.

62. Guo, Y., et al. 2007. Blocking Wnt/LRP5 signaling by a soluble receptor modulates the epithelial to mesenchymal transition and suppresses met and metalloproteinases in osteosarcoma Saos- 2 cells. J. Orthop. Res. 25:964-971.

63. Sagare, A., et al. 2007. Clearance of amyloid-beta by circulating lipoprotein receptors. Nat. Med. 13:1029-1031.

64. Wilsie, L.C., and Orlando, R.A. 2003. The low density lipoprotein receptor-related protein complexes with cell surface heparan sulfate proteoglycans to regulate proteoglycan-mediated lipoprotein catabolism. J. Biol. Chem. 278:15758-15764.

65. Beutler, B. 2002. TLR4 as the mammalian endotoxin sensor. Curr. Top. Microbiol. Immunol. 270:109-120.

66. Jo, M., Thomas, K.S., Wu, L., and Gonias, S.L. 2003. Soluble urokinase-type plasminogen activator receptor inhibits cancer cell growth and invasion by direct urokinase-independent effects on cell signaling. J. Biol. Chem. 278:46692-46698. 
67. Grimsley, P.G., Quinn, K.A., and Owensby, D.A. 1998. Soluble low-density lipoprotein receptorrelated protein. Trends Cardiovasc. Med. 8:363-368.

68. Hayashi, H., Campenot, R.B., Vance, D.E., and Vance, J.E. 2007. Apolipoprotein E-containing lipoproteins protect neurons from apoptosis via a signaling pathway involving low-density lipoprotein receptor-related protein-1. J. Neurosci. 27:1933-1941

69. Macdonald, R., Bingham, S., Bond, B.C., Parsons, A.A., and Philpott, K.L. 2001. Determination of changes in mRNA expression in a rat model of neuropathic pain by Taqman quantitative RT-PCR Brain Res. Mol. Brain Res. 90:48-56.

70. Campana, W.M., et al. 2006. Erythropoietin reduces Schwann cell TNF- $\alpha$, Wallerian degeneration and pain- related behaviors after peripheral nerve injury. Eur. J. Neurosci. 23:617-626.

71. Ranganathan, S., et al. 2004. Serine and threonine phosphorylation of the low density lipoprotein receptor-related protein by protein kinase Calpha regulates endocytosis and association with adaptor molecules. J. Biol. Chem. 279:40536-40544.

72. Herz, J., Goldstein, J.L., Strickland, D.K., Ho, Y.K., and Brown, M.S. 1991. 39-kDa protein modulates binding of ligands to low density lipoprotein receptor-related protein/alpha 2 -macroglobulin receptor. J. Biol. Chem. 266:21232-21238.

73. Hiraiwa, M., Taylor, E., Campana, W.M., Darin S.J., and O'Brien, J.S. 1997. Cell death prevention, mitogen-activated protein kinase stimulation and increased sulfatide concentrations in Schwann cells and oligodendrocytes by prosaposin and prosaptides. Proc. Natl. Acad. Sci. U. S. A. 94:4778-4781.

74. Liu, B., et al. 2001. Molecular consequences of activated microglia in the brain: overactivation induces apoptosis. J. Neurochem. 77:182-189.

75. Campana, W.M., Darin, S.J., and O'Brien, J.S. 1999. Phosphatidylinositol 3-kinase and Akt protein kinase mediate IGF-I- and prosaptide-induced sur- vival in Schwann cells. J. Neurosci. Res. 57:332-341. 76. Laemmli, U.K. 1970. Cleavage of structural proteins during the assembly of the head of bacteriophage T4. Nature. 227:680-685.

77. Campana, W.M., and Myers, R.R. 2001. Erythropoietin and erythropoietin receptors in the peripheral nervous system: changes after nerve injury. FASEB J. 15:1804-1806.

78. Livak, K.J., and Schmittgen, T.D. 2001. Analysis of relative gene expression data using real-time quantitative PCR and the 2(-Delta Delta C(T)) Method. Methods. 25:402-408.

79. Pfaffl, M.W. 2001. A new mathematical model for relative quantification in real-time RT-PCR. Nucleic Acids Res. 29:e45.

80. Chattopadhyay, S., Myers, R.R., Janes, J., and Shubayev, V. 2007. Cytokine regulation of MMP-9 in peripheral glia: implications for pathological processes and pain in injured nerve. Brain Behav. Immun. 21:561-568. 